\title{
Effects of Red Blood Cell Transfusions on the Risk of Developing Complications or Death: An Observational Study of a Cohort of Very Low Birth Weight Infants
}

\author{
Stefano Ghirardello, MD ${ }^{1}$ Elisa Dusi, MD ${ }^{1}$ Ivan Cortinovis, MD ${ }^{2}$ Stefania Villa, MD \\ Monica Fumagalli, MD ${ }^{1}$ Massimo Agosti, MD ${ }^{4}$ Silvano Milani, MD ${ }^{2}$ Fabio Mosca, MD ${ }^{1}$ \\ ${ }^{1}$ Neonatal intensive Care Unit, Department of Clinical Sciences and \\ Community Health, Fondazione IRCCS Ca'Granda Ospedale Maggiore \\ Policlinico, Milan, Italy \\ 2 Department of Clinical Sciences and Community Health, Laboratory \\ G. Maccacaro, Universita' degli Studi di Milano, Milano, Italy \\ 3 Immunoheamatology and Transfusion Centre, Fondazione IRCCS Ca' \\ Address for correspondence Stefano Ghirardello, MD, Neonatal \\ Intensive Care Unit, Department of Clinical Sciences and Community \\ Health, Fondazione IRCCS Ca' Granda Ospedale Maggiore Policlinico, \\ UNiversità degli Studi di Milano, Milan, Italy \\ (e-mail: stefano.ghirardello@mangiagalli.it). \\ Granda Ospedale Maggiore Policlinico, Milano, Italy \\ ${ }^{4}$ Maternal and Child Health Department, Del Ponte Hospital, \\ A.O. Di Circolo Fondazione Macchi, Varese, Italy \\ Am J Perinatol
}

\begin{abstract}
Keywords

- RBC transfusions

- newborn

- retinopathy

- bronchopulmonary dysplasia

- necrotizing enterocolitis

Background The aim of this study was to evaluate the association between red blood cell (RBC) transfusions on the risk of death, retinopathy of prematurity (ROP), bronchopulmonary dysplasia (BPD), and necrotizing enterocolitis (NEC) in very low birth weight (VLBW) infants.

Study Design and Methods This is an observational study. Data were entered prospectively into the study database at the time of the first transfusion. Clinical characteristics, adverse events, and outcomes of the patients transfused in the first 28 days of life were compared with the population of VLBW infants not transfused during the same period. The association among birth weight, gestational age, comorbidities, and the number of transfusions was estimated with a Poisson regression model. The association between the composite outcome and the occurrence of death, ROP, or BPD separately considered and a set of covariates was estimated with a logistic regression model.

Results We enrolled 641 VLBW infants, $42 \%$ of whom were transfused. Transfusions were associated with the risk of developing the composite outcome, independently from other conditions; this risk correlated with several transfusions $\geq 3$ (odds ratio: 5.88, 95\% confidence interval: $2.74-12.6$ ). ROP and BPD were associated with several transfusions $\geq 3$.

Conclusion We observed an association between RBC transfusions and the composite risk of death or ROP, BPD, and NEC.
\end{abstract}

ISSN 0735-1631. 
Red blood cell (RBC) transfusion is an important supportive therapy in the neonatal period. Nearly $40 \%$ of preterm newborns with birth weight (BW) between 1,000 and 1,500 g (very low BW [VLBW]) and more than 90\% weighing less than $1,000 \mathrm{~g}$ (extremely low BW [ELBW]) receive at least one blood transfusion during their hospital stay. ${ }^{1-4}$ The most common rationale for transfusing packed $\mathrm{RBC}$ in preterm infants is to improve oxygen delivery. Many neonatal intensive care units (NICUs) adopt transfusion guidelines based on hemoglobin or hematocrit levels combined with clinical conditions, days of life, and the need for respiratory or oxygen supports. However, no biochemical or instrumental tests have identified a target hemoglobin or hematocrit below which an RBC transfusion can definitely provide benefits to premature newborns. ${ }^{2,3,5-13}$ Furthermore, there is a growing body of evidences that RBC transfusions could be harmful. Studies in adult and pediatric patients found a significant association between RBC transfusion and increased mortality or morbidity. ${ }^{14-19}$ In the past few years, evidence for a negative effect of RBC transfusions was also reported in neonatal clinical practices. dos Santos et al observed that RBC transfusions in VLBW infants were associated with higher risk of death ${ }^{20}$ and many observational studies suggest a temporal relationship between RBC transfusion and the development of necrotizing enterocolitis (NEC) and germinal matrix hemorrhage-intraventricular hemorrhage (GMH-IVH) in VLBW infants. ${ }^{21-29}$ Various hypotheses have been advocated for these associations, but none of them has yet been confirmed. The introduction of gamma irradiation and leukocyte reduction from RBC before storage was demonstrated to reduce the incidence of retinopathy of prematurity (ROP) and bronchopulmonary dysplasia (BPD) in newborns weighing less than $1,250 \mathrm{~g} .{ }^{30}$ The use of RBC units with a short period of storage has been associated with lower morbidity and mortality in adult and pediatric patients, ${ }^{31-33}$ but these advantages were not confirmed in premature newborns. ${ }^{34}$ The cause-and-effect relationship of RBC transfusion with adverse clinical outcomes is difficult to establish due to numerous multiple confounding factors. Two randomized trials ${ }^{2,12}$ did not find differences in death, ROP, BPD, or NEC between patients transfused with different transfusion threshold; various observational trials in premature and VLBW infants ${ }^{14-19,34-36}$ suggested a worsening of short- and longterm prognoses in the most transfused infants, but definitive conclusions have yet to be drawn. Our study investigates the hypothesis that RBC transfusions are associated with an increased risk of death or the development of NEC, ROP, and BPD in a large cohort of VLBW infants.

\section{Materials and Methods}

Inclusion criteria: This single-center longitudinal study enrolled all infants with $\mathrm{BW} \leq 1,500 \mathrm{~g}$ born between January 2007 and December 2012 at our institution or outborn admitted to our NICU within 6 hours of life. Exclusion criteria: Infants with major congenital anomalies, chromosomal defects, metabolic diseases, congenital heart disease, born from human immunodeficiency virus-positive mothers, and dead in the first 24 hours of life were excluded.

\section{Data Collection and Definitions}

Neonates included in the study underwent transfusion according to our institutional transfusion guidelines in force since 2006 and unchanged during the study period (-Table 1). Data collected from electronic medical records were entered prospectively into the study database at the time of the first transfusion and updated after every RBC transfusion. Data of not transfused VLBW admitted to our NICU during the same time lapse were collected retrospectively at the end of each year. Clinical characteristics, adverse events, and outcomes of the VLBW infants transfused in the first 28 days of life were compared with the population of VLBW not transfused during the same time lapse. We analyzed the following neonatal characteristics: gestational age (GA); BW; Apgar score at 1 and 5 minutes of life; small for GA (SGA) defined as a $\mathrm{BW}<10$ th percentile for $\mathrm{GA}$, need for intubation in the delivery room, twins and multiples, days of mechanical ventilation (when more than 5 days), pharmacological treatment of patent ductus arteriosus (ibuprofen or indomethacin), each pretransfusion hemoglobin ( $\mathrm{g} / \mathrm{dL}$ ) in the first 28 days of life, need for major surgery during the first 28 days of life, any grade of GMH-IVH detected by cranial ultrasound, sepsis (defined by positive blood culture), duration of hospitalization, death or the presence of ROP, BPD, and NEC. Sepsis, intraventricular hemorrhage (IVH) 3 and 4 degrees grade, mechanical ventilation $>5$ days, intubation in the delivery room, and major surgery in the first 14 days were considered the most significant risk factors associated with a higher RBC transfusion rate and were aggregated in a single variable. ROP was diagnosed according to the International Classification of ROP; we recorded only cases of ROP grade $\geq 2$. BPD was defined according to the criteria proposed by Jobe and Bancalari at 36 weeks corrected age. ${ }^{37}$ NEC was diagnosed on the basis of clinical and radiographic findings according to the modified Bell's staging criteria. During the study period, feeding was not interrupted during

Table 1 Institutional guidelines for RBC transfusion in VLBW infants

\begin{tabular}{|l|}
\hline $\begin{array}{l}\text { Mechanical ventilation or noninvasive ventilation } \\
\text { requiring } \mathrm{FiO}_{2}>\mathbf{0 . 4} \text { : consider } \mathrm{RBC} \text { transfusion if } \\
\text { hematocrit }<\mathbf{4 0 \%}\end{array}$ \\
\hline Spontaneous breathing \\
\hline Age $<15 \mathrm{~d}$ : consider $\mathrm{RBC}$ transfusion if hematocrit $<35 \%$ \\
\hline $\begin{array}{l}\text { Age } 15-28 \mathrm{~d} \text { : consider RBC transfusion if } \\
\text { hematocrit }<30 \%\end{array}$ \\
\hline $\begin{array}{l}\text { Age }>28 \mathrm{~d} \text { : consider } \mathrm{RBC} \text { transfusion if hematocrit }<25 \% \\
\text { and reticulocyte count }<100,000 / \mathrm{mL}\end{array}$ \\
\hline $\begin{array}{l}\text { Consider RBC transfusion, independently from hematocrit } \\
\text { values, if }\end{array}$ \\
\hline $\begin{array}{l}\text { Symptoms of anemia (poor growth, apneas, tachycardia, } \\
\text { heart murmur) }\end{array}$ \\
\hline Hypovolemia \\
\hline Major surgical procedure \\
\hline
\end{tabular}

Abbreviations: RBC, red blood cell; VLBW, very low birth weight. 
RBC transfusions. All RBC units were collected from repeat voluntary donors. Whole blood donations were collected into $63 \mathrm{~mL}$ of citrate phosphate dextrose anticoagulant. RBCs were obtained by centrifugation at $22 \pm 2^{\circ} \mathrm{C}$ at $1,750 \mathrm{rpm}(1,000 \mathrm{~g})$ for 7 minutes followed by the removal of supernatant plasma and buffy coat and resuspension in $100 \mathrm{~mL}$ of saline-adenineglucose-mannitol (SAGM) additive solution. Leukocyte reduction was performed before storage and irradiation immediately before transfusion. The packed RBCs were transfused within 5 days of collection in small aliquots of 10 to $20 \mathrm{~mL} / \mathrm{kg}$, slowly in 4 hours. None of the patients received erythropoietic drugs in the first month of life.

\section{Statistical Analysis}

Differences and 95\% confidence interval $(\mathrm{CI})$ in the conditions at birth, morbidity, and outcome within the 28th day of life between not transfused and transfused neonates were computed with Pearson chi-square test and Fisher exact test in the whole group of newborns enrolled and in the ELBW subgroup. To investigate the role of transfusions in the development of the outcomes considered, independently from illness severity, we introduced a dichotomous variable (comorbidities) which included sepsis, IVH 3 and 4 degrees grade, mechanical ventilation $>5$ days, intubation in the delivery room, and major surgery in the first 14 days. The association among BW, GA, the presence of at least one comorbidity, and the number of transfusions performed within the 28th day of life was estimated with a multivariable Poisson regression model for both transfused and not transfused infants. Results were expressed as mean and $95 \% \mathrm{CI}$. The association between the composite outcome (death, ROP, BPD, or NEC) and a set of covariates was estimated with a logistic regression model. The set included BW, GA, comorbidities (model 1), and number of transfusions (model 2). The results were expressed as odds ratios (OR) and 95\% CI. An analogous model was used to estimate the association between the occurrence of death, ROP, or BPD separately considered and the above covariates. NEC was not considered since it occurred in 15 cases only.

\section{Results}

During the study period, 765 VLBW infants were admitted to our NICU; 124 were excluded because they did not meet the inclusion criteria. Patients enrolled in the study were 641, 241 of whom (37.6\%) were ELBW infants. Mean GA was 29.4 (standard deviation $[\mathrm{SD}]=3$ ) weeks with a mean BW of 1,107 (SD = 303) g. SGA newborns represented $35 \%$ of the entire group. Twins represented $46.8 \%$ of the sample. SGA newborns represented 35\% of the entire group. Death occurred in $9 \%$ of the sample but in $21 \%$ of ELBW patients. Fortytwo percent of the patients were transfused at least once in the first 28 days of life; this percentage rose to $80.5 \%$ for the ELBW category. Univariate statistical analysis showed that GA, BW, Apgar score at 1 and 5 minutes, need for resuscitation in the delivery room, mechanical ventilation for more than 5 days, major surgery, incidence of pharmacologically treated PDA, proven sepsis, length of stay, GMH-IVH grade 3 or 4 , death, BPD, and ROP were significantly higher in the transfused group (-Tables 2 and 3); these differences were confirmed when ELBW infants were analyzed separately. NEC, with an incidence of $2 \%$ in the entire sample, was equally distributed between the two groups. Twins and SGA newborns were more likely not to be transfused in the first 28 days. About $80 \%$ of ELBW infants transfused developed at least one of the following comorbidities: sepsis, third and fourth grades IVH, mechanical ventilation $>5$ days, intubation in the delivery room, major surgery in the first 14 days, compared with $25.5 \%$ of neonates not transfused $(p<0.0001)$. All ELBW neonates with third and fourth grade IVH were transfused. ROP developed in $42 \%$ of ELBW infants transfused, compared with $12.7 \%$ not transfused $(p<0.0002)$; BPD and death occurred more frequently in transfused ELBW newborns compared with not transfused (32 vs. $2 \%, p<0.0001$ and 24 vs. $8.5 \%, p=0.018$, respectively) (-Table 4). Patients with GA $\leq 28$ weeks, BW $\leq 1,000 \mathrm{~g}$ and with comorbidities had significantly higher transfusion needs, as shown in - Table 5. Mean pretransfusion hemoglobin was $9.6 \pm 1.1 \mathrm{~g} / \mathrm{dL}$; mean $\mathrm{RBC}$ storage time was 3.1 days. As shown in - Table 6 (model 1 ), GA $\leq 28$ weeks, BW $\leq 1,000$ $\mathrm{g}$, and the presence of comorbidities were all associated with higher risk of developing the composite outcome considered. The inclusion of the number of RBC transfusions (model 2) showed that transfusions influenced the risk of developing the composite outcome, both for several transfusions $\leq 2$ (OR: 3.38; 95\% CI: 1.74-6.55) and $\geq 3$ (OR: 5.88; 95\% Cl: 2.74-12.6). The risk of developing an adverse outcome

Table 2 Baseline characteristics for continuous variables

\begin{tabular}{|l|l|l|l|}
\hline & $\begin{array}{l}\text { Not transfused within 28 d } \\
\text { (no. = 372) } \\
\text { Mean (SD) }\end{array}$ & $\begin{array}{l}\text { 95\% Cl for differences } \\
\text { “not transfused vs. transfused” }\end{array}$ & $\begin{array}{l}\text { Transfused within 28 d } \\
\text { (no. }=269) \\
\text { Mean (SD) }\end{array}$ \\
\hline Birth weight (g) & $1,271.2(197)$ & $353.8 ; 427.3$ & $880.6(276)$ \\
\hline Gestational age (wk) & $31.2(2.1)$ & $3.9 ; 4.6$ & $26.9(2.3)$ \\
\hline Apgar 1 (score) & $7.0(1.6)$ & $\mathbf{1 . 7} ; 2.26$ & $5.0(2.1)$ \\
\hline Apgar 5 (score) & $8.6(1.1)$ & $\mathbf{0 . 7 7} 1.15$ & $7.6(1.4)$ \\
\hline Length of stay (d) & $45.0(15.9)$ & $-54.3 ;-40.9$ & $92.6(63.2)$ \\
\hline
\end{tabular}

Abbreviations: $\mathrm{Cl}$, confidence interval; SD, standard deviation.

Note: 95\% confidence interval for mean differences not transfused versus transfused. Statistically significant differences are in bold. 
Red Blood Cell Transfusions in Very Low Birth Weight Infants Ghirardello et al.

Table 3 Baseline characteristics for dichotomous variables

\begin{tabular}{|l|l|l|l|}
\hline & $\begin{array}{l}\text { Not transfused within } \\
28 \mathrm{~d}(\mathrm{no.}=372) \\
\text { No. (\%) }\end{array}$ & $\begin{array}{l}\text { 95\% Cl for differences } \\
\text { “not transfused vs. transfused" }\end{array}$ & $\begin{array}{l}\text { Transfused within } \\
\mathbf{2 8} \mathrm{d} \text { (no. }=269) \\
\text { No. (\%) }\end{array}$ \\
\hline Twin & $182(48.9)$ & $-3.1 ; 13.2$ & $118(43.9)$ \\
\hline SGA & $160(43.0)$ & $-11.7 ;-26.7$ & $64(23.8)$ \\
\hline PDA & $53(14.3)$ & $-56.7 ;-42.5$ & $172(63.9)$ \\
\hline Major surgery within 28 d & $3(0.8)$ & $-19.5 ;-10.1$ & $42(15.6)$ \\
\hline Intubation in the delivery room & $27(7.3)$ & $-51.3 ;-33.6$ & $139(51.7)$ \\
\hline Sepsis & $12(3.2)$ & $-24.7 ;-13.6$ & $60(22.3)$ \\
\hline GMH-IVH 3-4 deg grade & $1(0.3)$ & $-17.1 ;-8.4$ & $35(13.0)$ \\
\hline Mechanical ventilation $>$ d & $61(16.4)$ & $-62.2 ;-48.5$ & $193(71.7)$ \\
\hline NEC & $5(1.3)$ & $-5.2 ; 0.5$ & $10(3.7)$ \\
\hline ROP grade $\geq 2$ & $19(5.1)$ & $-35.1 ;-22.3$ & $91(33.8)$ \\
\hline BPD & $6(1.6)$ & $-31.3 ;-19.2$ & $65(26.9)$ \\
\hline Death & $5(1.3)$ & $-23.6 ;-13.1$ & $53(19.7)$ \\
\hline
\end{tabular}

Abbreviations: BPD, bronchopulmonary dysplasia; $\mathrm{Cl}$, confidence interval; $\mathrm{GMH}$-IVH, germinal matrix hemorrhage-intraventricular hemorrhage; NEC, necrotizing enterocolitis; PDA, patent ductus arteriosus; ROP, retinopathy of prematurity; SGA, small for gestational age.

Note: $95 \%$ confidence interval for percentage differences "not transfused versus transfused". Statistically significant differences are in bold.

ascribable to transfusions was quantified in $2.5 \%$ (difference between model $2: R^{2}=59.0 \%$ and model $1: R^{2}=56.5 \%$ ). The associations between ROP, BPD, and mortality, singly considered, and the above covariates were shown in - Table 7. None of the infants who developed NEC during the study period had been transfused in the 48 hours before the onset of symptoms.

\section{Discussion}

We observed an association between RBC transfusions in the first 28 days of life and the risk of developing the composite outcome of death, ROP, BPD, or NEC in a cohort of VLBW infants; transfusions were also associated with ROP grade $\geq 2$ and BPD, separately analyzed. We performed a control for gestational age, BW, and illness severity (i.e., sepsis, GMH-IVH grade $\geq 3$, mechanical ventilation for at least 5 days, major surgery, and intubation in the delivery room), as these conditions are associated with higher transfusion needs, and, at the same time, are main determinants for the outcomes considered. Our data showed a correlation between outcomes and the number of transfusions performed, independently from other variables, and weighted the effect of transfusions in the development of the outcomes considered. The association between RBC transfusion and increased mortality rate was described by dos Santos et al in a cohort of more than 1,000 VLBW infants; they reported a 1.49 times higher risk of death in patients transfused in the first month of life compared with infants who were not, and the risk increased for those infants transfused more than twice in the period considered. ${ }^{25}$ Our study did not confirm this association; this could be due to the difference in mortality rates between the two cohorts (9 vs. $27.8 \%$ ). Another difference between the two studies is related to transfusion practices: our patients were transfused according to the same institutional guidelines, where in the multicenter trial

Table 4 Outcomes of ELBW neonates "not transfused" versus "transfused within 28 days of life"

\begin{tabular}{|l|l|l|l|}
\hline & $\begin{array}{l}\text { Not transfused within } \\
28 \mathrm{~d}(\mathrm{no.}=47) \\
\text { No. (\%) }\end{array}$ & $\begin{array}{l}\text { 95\% Cl for differences not } \\
\text { transfused vs. transfused }\end{array}$ & $\begin{array}{l}\text { Transfused within } \\
\text { 28 d (no. = 194) } \\
\text { No. (\%) }\end{array}$ \\
\hline ROP grade $\geq 2$ & $6(12.8)$ & $-42.6 ; 16.4$ & $82(42.3)$ \\
\hline BPD & $1(2.1)$ & $-35.1 ;-17.3$ & $55(28.3)$ \\
\hline GMH-IVH 3-4 deg grade & $0(0)$ & $-21.3 ;-8.6$ & $29(14.9)$ \\
\hline NEC & $1(2.1)$ & $-7.1 ; 5.1$ & $6(3.1)$ \\
\hline Death & $4(8.5)$ & $-27.0 ;-4.4$ & $47(24.2)$ \\
\hline
\end{tabular}

Abbreviations: BPD, bronchopulmonary dysplasia; $\mathrm{Cl}$, confidence interval; ELBW, extremely low birth weight; GMH-IVH, germinal matrix hemorrhageintraventricular hemorrhage; NEC, necrotizing enterocolitis; ROP, retinopathy of prematurity.

Note: Statistically significant differences are in bold. 
Red Blood Cell Transfusions in Very Low Birth Weight Infants Ghirardello et al.

Table 5 Estimated number of transfusions as a function of GA, BW, and comorbidities (multivariable Poisson model)

\begin{tabular}{|l|l|l|}
\hline Variables & Mean no. of transfusions & 95\% Cl for mean \\
\hline $\mathrm{GA} \leq 28 \mathrm{wk}$ & 2.19 & $1.96-2.45$ \\
\hline $\mathrm{GA}>28 \mathrm{wk}$ & 0.61 & $0.52-0.72$ \\
\hline $\mathrm{BW} \leq 1,000 \mathrm{~g}$ & 2.04 & $1.83-2.28$ \\
\hline $\mathrm{BW}>1,000 \mathrm{~g}$ & 0.66 & $0.57-0.76$ \\
\hline Comorbidities = yes & 1.93 & $1.74-2.14$ \\
\hline Comorbidities = no & 0.69 & $0.60-0.80$ \\
\hline
\end{tabular}

Abbreviations: BW, birth weight; $\mathrm{Cl}$, confidence interval; GA, gestational age.

Note: Comorbidity = yes means the presence of at least one condition among sepsis, intraventricular hemorrhage 3 and 4 degrees grade, mechanical ventilation $>5$ days, intubation in the delivery room, major surgery within 14 days of life. Statistically significant differences are in bold.

Table 6 Composite outcome (death or complications) as a function of GA, BW, comorbidities (model 1) and number of transfusions (model 2)

\begin{tabular}{|l|l|l|l|l|}
\hline & \multicolumn{2}{|l|}{ Model $1 R^{2}=0.5649$} & \multicolumn{2}{l|}{ Model $2 R^{2}=0.5905$} \\
\hline Variables & OR & $95 \%$ Cl for OR & OR & $95 \%$ CI for OR \\
\hline $\mathrm{GA}: \leq 28$ vs. $>28$ wk & 6.61 & $3.96-11.07$ & 3.69 & $2.08-6.54$ \\
\hline BW: $\leq 1,000$ vs. $>1,000 \mathrm{~g}$ & 4.11 & $2.51-6.74$ & 2.63 & $1.53-4.52$ \\
\hline Comorbidities: yes vs. no & 4.30 & $2.65-6.99$ & 2.97 & $1.76-4.99$ \\
\hline No. of transfusions: $1-2$ vs. 0 & & & 3.38 & $1.74-6.55$ \\
\hline No. of transfusions: $\geq 3$ vs. 0 & & & 5.88 & $2.74-12.60$ \\
\hline
\end{tabular}

Abbreviations: BW, birth weight; $\mathrm{Cl}$, confidence interval; GA, gestational age; OR, odds ratio.

Note: Composite risk of death or complications: at least one among death, retinopathy of prematurity grade $\geq 2$, bronchopulmonary dysplasia, and necrotizing enterocolitis. Statistically significant differences are in bold.

by dos Santos et al, RBC transfusions were not standardized for each center participating in the study. Possible differences in transfusion practices among hospitals may have affected the results. In the past years, many observational studies highlighted a possible temporal association between RBC transfusion in the neonatal period and the development of NEC. ${ }^{21-27}$ Accordingly, we previously described four cases of transfusion-related NEC, not included in this sample because they did not meet the inclusion criteria. ${ }^{38}$ Different hypotheses have been proposed to explain this association: (1) chronic anemia with a mechanism of hypoperfusion and reperfusion, (2) enteral nutrition that could reduce mesenteric blood flow during RBC transfusion, (3) exposure to biologically active mediators accumulated during storage, and (4) impaired gut microcirculation and tissue hypoxia secondary to prolonged storage that increases RBC adhesion and depletes erythrocyte nitric oxide. However, none of these hypotheses has been definitively confirmed. The present study did not confirm this association and two recent reports showed similar results ${ }^{39,40}$; the lack of association between

Table 7 Occurrence of death, ROP, BPD as a function of GA, BW, comorbidities, and number of transfusions

\begin{tabular}{|l|l|l|l|l|l|l|}
\hline & \multicolumn{2}{|l|}{$\begin{array}{l}\text { Death } \\
R^{2}=\mathbf{0 . 4 0 2 6}\end{array}$} & \multicolumn{2}{l|}{$\begin{array}{l}\text { ROP grade } \geq 2 \\
R^{2}=0.4187\end{array}$} & \multicolumn{2}{l|}{$\begin{array}{l}\text { BPD } \\
R^{2}=0.4560\end{array}$} \\
\hline Variables & OR & $\mathbf{9 5 \%}$ Cl for OR & OR & 95\% CI for OR & OR & 95\% CI for OR \\
\hline GA: $\leq 28$ vs. $>28$ wk & 3.11 & $1.18-8.21$ & 8.36 & $3.55-19.68$ & 1.62 & $0.64-4.07$ \\
\hline BW: $\leq 1,000$ vs. $>1,000 \mathrm{~g}$ & 5.94 & $2.31-15.26$ & 1.67 & $0.86-3.25$ & 1.28 & $0.55-2.95$ \\
\hline Comorbidities: yes vs. no & 20.38 & $4.66-89.16$ & 0.67 & $0.36-1.25$ & 17.30 & $5.00-59.86$ \\
\hline No. of transfusions: $1-2$ vs. 0 & 0.86 & $0.75-8.85$ & 1.87 & $0.73-4.76$ & 1.08 & $0.32-3.63$ \\
\hline No. of transfusions: $\geq 3$ vs. 0 & 2.58 & $\mathbf{0 . 2 4 - 3 . 1 7}$ & $\mathbf{5 . 1 3}$ & $1.92-13.67$ & $\mathbf{5 . 4 0}$ & $1.57-18.63$ \\
\hline
\end{tabular}

Abbreviations: BPD, bronchopulmonary dysplasia; BW, birth weight; Cl, confidence interval; GA, gestational age; ROP, retinopathy of prematurity. Note: Statistically significant differences are in bold. 
NEC and RBC transfusions in our patients could be related to the very low incidence of NEC, compared with other studies. Two recent meta-analysis of observational and randomized trials have come to different conclusions; the pooled results from randomized trials supported a correlation between low $\mathrm{RBC}$ transfusion rate and the development of $\mathrm{NEC},{ }^{41}$ but no time correlations between transfusion and the development of NEC were possible. These results contrasted with those drawn from the meta-analysis of observational studies by Mohamed and Shah et $\mathrm{al}^{24}$ that confirmed the temporal correlation between the two events. Recently, a multicenter, randomized trial ${ }^{34}$ showed no statistical differences for the composite risk of NEC, ROP, BPD, GMH-IVH, and death in newborns with $\mathrm{BW} \leq 1,250 \mathrm{~g}$ randomized to be transfused with RBC units stored for a mean time of 5.1 days versus standard issue RBCs (14.6 days), thus excluding a possible role for standard storage time in the development of complications of prematurity. GMH-IVH has been recently associated with early RBC transfusions in neonatal life. ${ }^{28,29}$ Reactive oxygen species, endothelial activation, capillary slugging in the germinal matrix, and increased capillary pressure due to mechanical or biochemical properties of banked RBC have been advocated as possible mechanisms of transfusion-related GMH-IVH. ${ }^{19}$ In our study, all ELBW newborns who developed severe IVH were transfused in the first month of life, but we were not able to investigate a temporal association between the two events. Delayed cord clamping and umbilical cord milking are well-known procedures to augment circulating RBC and hemoglobin. Both are associated with a reduction in the incidence of IVH and NEC. ${ }^{42-44}$ According to these observations, that some cases of IVH and NEC are preceded by a RBC transfusion, one possible mechanism to explain the benefits derived from placental transfusion is the reduction in transfusion needs in the first week of life. Recently, a possible role for anemia and RBC transfusion in the development of ROP has been reported although evidences are contrasting. ${ }^{12,45,46}$ Blood transfusions are supposed to increase the risk of ROP by augmenting retinal oxygen levels; another pathophysiological mechanism attributed to RBC transfusion is free iron overload that could contribute to the production of free oxygen radicals directly responsible for the damage to the developing retinal vessels. ${ }^{36,47}$ Our study supports a significant association between ROP grade $\geq 2$ and several transfusions higher than two, both in VLBW and ELBW infants. These data are in agreement with the hypothesis suggested by Dani et al in a prospective observational study where they demonstrated that blood transfusion volume and iron loaded by transfusions increased the risk of ROP. $^{47}$ Valieva et $\mathrm{al}^{48}$ did not find associations between volume or number of transfusions and the incidence of ROP in 60 ELBW patients retrospectively reviewed; however, a significant association with the severity of the disease was observed. A randomized controlled trial by Brooks et al comparing 50 newborns with $\mathrm{BW} \leq 1,250 \mathrm{~g}$ transfused with two transfusion regimes based on hematocrit $(<30$ vs. $>40 \%$ ) failed in demonstrating any association among hemoglobin, hematocrit, and incidence of $\mathrm{ROP}^{49}$ but the small number of patients enrolled may have affected these results. We found a significant association between RBC transfusion and the development of BPD. This effect correlated with the number of transfusions performed. Similar results were reported by Chen et $\mathrm{al}^{13}$ in a randomized trial, where patients receiving more than $30 \mathrm{~mL}$ of RBC in the first month of life resulted to have higher risk of developing BPD, compared with infants treated with a more restrictive regimen. A possible role for oxidative cellular stress mediated by free oxygen radicals has been advocated in the physiopathology of ROP and BPD. Newborns are currently transfused with RBC from adult donors, where hemoglobin A has lower affinity for oxygen compared with fetal hemoglobin. Therefore, RBC transfusion could augment the risk of "oxygen radicals disease of the newborn" through a "nonphysiologic" oxygen released to tissues, as recently suggested by Bianchi et al. ${ }^{50}$ Theoretically, allogeneic umbilical RBC transfusions may play a protective role in the development of complications associated with oxidative damages, particularly in the most premature infants. This intriguing hypothesis should be tested in future randomized trials. The main limitation of this study is the introduction of a selection bias related to the fact that patients transfused are sicker and the outcomes considered are strongly related to comorbidities; thus, transfusions could be only a marker for illness severity. However, the variables related to illness severity were adjusted by using the most significant clinical variables associated with increased transfusion needs, morbidity, and mortality. The logistic regression model showed that RBC transfusion contributed to the development of the adverse outcomes considered independently from clinical conditions. It is important to point out that, although significant, the contribution of transfusions to the development of complications of prematurity was smaller, compared with GA, BW, and the presence of comorbidities. In the past years, two randomized trials ${ }^{2,12}$ that investigated different transfusion thresholds did not find significant associations between number of transfusions and the development of death, ROP, BPD, and NEC. The study by Bell et al ${ }^{12}$ was designed to assess primarily the differences in transfusion needs between two transfusion thresholds in 100 newborns with BW less than 1,300 g. Infants in the liberal group received more $\mathrm{RBC}$ transfusions compared with the restrictive group; the latter showed a higher rate of periventricular leukomalacia and intraparenchymal hemorrhage and a trend to develop fewer cases of ROP and BPD. The premature infant in need of transfusion (PINT) trial ${ }^{2}$ enrolled 451 ELBW infants to two transfusional regimens to investigate differences in the composite outcome of death or ROP, BPD, and NEC. In our opinion, this study did not allow to draw definitive conclusions about the possible correlation between number of transfusions and outcomes because there were no statistical differences in the number of transfusions performed between the two arms of the trial. A recent metaanalysis by Ibrahim et $\mathrm{al}^{35}$ concluded that a restrictive RBC transfusion threshold resulted in a significant lower number of transfusions and donor exposures and can be used without incurring in clinically important increase in the risk of death or major short-term neonatal morbidities. In their review, Whyte and Kirpalani came to more prudent conclusions ${ }^{51}$ 
suggesting to avoid hemoglobin levels below the lower limits tested, given the uncertainties of the available data; however, they state that a restrictive practice does not appear to have a significant impact on death or major morbidities. Long-term neurodevelopment outcomes from the patients enrolled in the PINT trial showed some weak evidence of benefits from the higher hemoglobin threshold group ${ }^{52}$; conversely, a statistically significant difference in associative verbal fluency, visual memory, and reading ability, favoring the restrictive threshold arm was reported in a subgroup of patients enrolled in the IOWA study, ${ }^{53}$ that was in contrast to the shortterm outcomes from the same group, that showed a lower rate of brain damage. The effects of transfusion thresholds on neurocognitive outcome of ELBW (EETNO) trial is ongoing ${ }^{54}$ and will contribute to clarify the long-term effects of transfusions at different hemoglobin threshold in ELBW infants. Our study highlights a significant association between RBC transfusions and short-term outcomes in VLBW infants. There are some plausible biologic explanations for a contribution of $\mathrm{RBC}$ transfusions to the development of complications of prematurity. However, it is possible that sicker infants are more likely to be transfused and therefore prone to develop complications. The observational nature of our study could not elucidate the eventual cause-effect relationships and large randomized trials are required to confirm the possible detrimental role of RBC transfusions in premature infants.

\section{Conflict of Interest}

None.

\section{Acknowledgment}

The authors would like to thank Paolo Rebulla (Fondazione IRCCS Ca' Granda Ospedale Maggiore Policlinico, Milan, Italy) for the critical review of the article.

\section{References}

1 Guillén U, Cummings JJ, Bell EF, et al. International survey of transfusion practices for extremely premature infants. Semin Perinatol 2012;36(4):244-247

2 Kirpalani H, Whyte RK, Andersen C, et al. The Premature Infants in Need of Transfusion (PINT) study: a randomized, controlled trial of a restrictive (low) versus liberal (high) transfusion threshold for extremely low birth weight infants. J Pediatr 2006;149(3): 301-307

3 Christensen RD, Ilstrup S. Recent advances toward defining the benefits and risks of erythrocyte transfusions in neonates. Arch Dis Child Fetal Neonatal Ed 2013;98(4):F365-F372

4 Chirico G. Red blood cell transfusion in preterm neonates. Current perspectives. Int J Clin Transfus Med 2014;2:21-28

5 Whyte RK, Jefferies AL; Canadian Paediatric Society, Fetus and Newborn Committee. Red blood cell transfusion in newborn infants. Paediatr Child Health (Oxford) 2014;19(4):213-222

6 von Lindern JS, Lopriore E. Management and prevention of neonatal anemia: current evidence and guidelines. Expert Rev Hematol 2014;7(2):195-202

7 Murray NA, Roberts IA. Neonatal transfusion practice. Arch Dis Child Fetal Neonatal Ed 2004;89(2):F101-F107
8 Plaisant F. Evolution of neonatal transfusion practices: current recommendations [in French]. Transfus Clin Biol 2011;18(2): 262-268

9 Gibson BES, Todd A, Roberts I, et al; British Committee for Standards in Haematology Transfusion Task Force: Writing Group. Transfusion guidelines for neonates and older children. $\mathrm{Br} \mathrm{J}$ Haematol 2004;124(4):433-453

10 Venkatesh V, Khan R, Curley A, New H, Stanworth S. How we decide when a neonate needs a transfusion. Br J Haematol 2013; 160(4):421-433

11 Venkatesh V, Khan R, Curley A, Hopewell S, Doree C, Stanworth S. The safety and efficacy of red cell transfusions in neonates: a systematic review of randomized controlled trials. $\mathrm{Br} \mathrm{J}$ Haematol 2012;158(3):370-385

12 Bell EF, Strauss RG, Widness JA, et al. Randomized trial of liberal versus restrictive guidelines for red blood cell transfusion in preterm infants. Pediatrics 2005;115(6):1685-1691

13 Chen HL, Tseng HI, Lu CC, Yang SN, Fan HC, Yang RC. Effect of blood transfusions on the outcome of very low body weight preterm infants under two different transfusion criteria. Pediatr Neonatol 2009;50(3):110-116

14 Kamper-Jørgensen M, Ahlgren M, Rostgaard K, et al. Survival after blood transfusion. Transfusion 2008;48(12):2577-2584

15 Hébert PC, Wells G, Blajchman MA, et al. A multicenter, randomized, controlled clinical trial of transfusion requirements in critical care. Transfusion Requirements in Critical Care Investigators, Canadian Critical Care Trials Group. N Engl J Med 1999;340(6): 409-417

16 Kneyber MC, Hersi MI, Twisk JW, Markhorst DG, Plötz FB. Red blood cell transfusion in critically ill children is independently associated with increased mortality. Intensive Care Med 2007; 33(8):1414-1422

17 Székely A, Cserép Z, Sápi E, et al. Risks and predictors of blood transfusion in pediatric patients undergoing open heart operations. Ann Thorac Surg 2009;87(1):187-197

18 Triulzi DJ. Transfusion-related acute lung injury: current concepts for the clinician. Anesth Analg 2009;108(3):770-776

19 Murphy GJ, Reeves BC, Rogers CA, Rizvi SI, Culliford L, Angelini GD. Increased mortality, postoperative morbidity, and cost after red blood cell transfusion in patients having cardiac surgery. Circulation 2007;116(22):2544-2552

20 dos Santos AM, Guinsburg R, de Almeida MF, et al; Brazilian Network on Neonatal Research. Red blood cell transfusions are independently associated with intra-hospital mortality in very low birth weight preterm infants. J Pediatr 2011;159(3):371-376. e1, 3

21 Wan-Huen P, Bateman D, Shapiro DM, Parravicini E. Packed red blood cell transfusion is an independent risk factor for necrotizing enterocolitis in premature infants. J Perinatol 2013;33(10): 786-790

22 La Gamma EF, Blau J. Transfusion-related acute gut injury: feeding, flora, flow, and barrier defense. Semin Perinatol 2012;36(4): 294-305

23 El-Dib M, Narang S, Lee E, Massaro AN, Aly H. Red blood cell transfusion, feeding and necrotizing enterocolitis in preterm infants. J Perinatol 2011;31(3):183-187

24 Mohamed A, Shah PS. Transfusion associated necrotizing enterocolitis: a meta-analysis of observational data. Pediatrics 2012; 129(3):529-540

25 Paul DA, Mackley A, Novitsky A, Zhao Y, Brooks A, Locke RG. Increased odds of necrotizing enterocolitis after transfusion of red blood cells in premature infants. Pediatrics 2011;127(4): 635-641

26 Blau J, Calo JM, Dozor D, Sutton M, Alpan G, La Gamma EF. Transfusion-related acute gut injury: necrotizing enterocolitis in very low birth weight neonates after packed red blood cell transfusion. J Pediatr 2011;158(3):403-409 
27 Christensen RD, Lambert DK, Henry E, et al. Is "transfusionassociated necrotizing enterocolitis" an authentic pathogenic entity? Transfusion 2010;50(5):1106-1112

28 Christensen RD, Baer VL, Lambert DK, Ilstrup SJ, Eggert LD, Henry E. Association, among very-low-birthweight neonates, between red blood cell transfusions in the week after birth and severe intraventricular hemorrhage. Transfusion 2014;54(1):104-108

29 Baer VL, Lambert DK, Henry E, Snow GL, Butler A, Christensen RD. Among very-low-birth-weight neonates is red blood cell transfusion an independent risk factor for subsequently developing a severe intraventricular hemorrhage? Transfusion 2011;51(6): 1170-1178

30 Fergusson D, Hébert PC, Lee SK, et al. Clinical outcomes following institution of universal leukoreduction of blood transfusions for premature infants. JAMA 2003;289(15):1950-1956

31 Cholette JM, Pietropaoli AP, Henrichs KF, et al. Longer RBC storage duration is associated with increased postoperative infections in pediatric cardiac surgery. Pediatr Crit Care Med 2015;16(3): 227-235

32 Koch CG, Li L, Sessler DI, et al. Duration of red-cell storage and complications after cardiac surgery. N Engl J Med 2008;358(12): 1229-1239

33 Frenzel T, Westphal-Varghese B, Westphal M. Role of storage time of red blood cells on microcirculation and tissue oxygenation in critically ill patients. Curr Opin Anaesthesiol 2009;22(2):275-280

34 Fergusson DA, Hébert P, Hogan DL, et al. Effect of fresh red blood cell transfusions on clinical outcomes in premature, very lowbirth-weight infants: the ARIPI randomized trial. JAMA 2012; 308(14):1443-1451

35 Ibrahim M, Ho SK, Yeo CL. Restrictive versus liberal red blood cell transfusion thresholds in very low birth weight infants: a systematic review and meta-analysis. J Paediatr Child Health 2014;50(2): $122-130$

36 Collard KJ. Transfusion related morbidity in premature babies: possible mechanisms and implications for practice. World J Clin Pediatr 2014;3(3):19-29

37 Jobe AH, Bancalari E. Bronchopulmonary dysplasia. Am J Respir Crit Care Med 2001;163(7):1723-1729

38 Ghirardello S, Lonati CA, Dusi E, Pugni L, Mosca F. Necrotizing enterocolitis and red blood cell transfusion. J Pediatr 2011;159(2): 354-355, author reply 355-356

39 Sharma R, Kraemer DF, Torrazza RM, et al. Packed red blood cell transfusion is not associated with increased risk of necrotizing enterocolitis in premature infants. J Perinatol 2014;34(11): 858-862

40 Wallenstein MB, Arain YH, Birnie KL, et al. Red blood cell transfusion is not associated with necrotizing enterocolitis: a review of consecutive transfusions in a tertiary neonatal intensive care unit. J Pediatr 2014;165(4):678-682

41 Kirpalani H, Zupancic JA. Do transfusions cause necrotizing enterocolitis? The complementary role of randomized trials and observational studies. Semin Perinatol 2012;36(4):269-276
42 Del Vecchio A, Henry E, D'Amato G, et al. Instituting a program to reduce the erythrocyte transfusion rate was accompanied by reductions in the incidence of bronchopulmonary dysplasia, retinopathy of prematurity and necrotizing enterocolitis. J Matern Fetal Neonatal Med 2013;26(Suppl 2):77-79

43 Baer VL, Lambert DK, Carroll PD, Gerday E, Christensen RD. Using umbilical cord blood for the initial blood tests of VLBW neonates results in higher hemoglobin and fewer RBC transfusions. J Perinatol 2013;33(5):363-365

44 Ghavam S, Batra D, Mercer J, et al. Effects of placental transfusion in extremely low birthweight infants: meta-analysis of long- and short-term outcomes. Transfusion 2014;54(4): 1192-1198

45 van Sorge A, Kerkhoff F, Halbertsma FJ, Schalij-Delfos N. Severe retinopathy of prematurity in twin-twin transfusion syndrome after multiple blood transfusions. Acta Ophthalmol (Copenh) 2014;92(2):e167-e168

46 Giannantonio C, Papacci P, Cota F, et al. Analysis of risk factors for progression to treatment-requiring ROP in a single neonatal intensive care unit: is the exposure time relevant? J Matern Fetal Neonatal Med 2012;25(5):471-477

47 Dani C, Reali MF, Bertini G, Martelli E, Pezzati M, Rubaltelli FF. The role of blood transfusions and iron intake on retinopathy of prematurity. Early Hum Dev 2001;62(1):57-63

48 Valieva OA, Strandjord TP, Mayock DE, Juul SE. Effects of transfusions in extremely low birth weight infants: a retrospective study. J Pediatr 2009;155(3):331-37.e1

49 Brooks SE, Marcus DM, Gillis D, Pirie E, Johnson MH, Bhatia J. The effect of blood transfusion protocol on retinopathy of prematurity: a prospective, randomized study. Pediatrics 1999;104(3 Pt 1):514-518

50 Bianchi M, Giannantonio C, Spartano S, et al. Allogeneic umbilical cord blood red cell concentrates: an innovative blood product for transfusion therapy of preterm infants. Neonatology 2015;107(2): 81-86

51 Whyte R, Kirpalani H. Low versus high haemoglobin concentration threshold for blood transfusion for preventing morbidity and mortality in very low birth weight infants. Cochrane Database Syst Rev 2011;11(11):CD000512

52 Whyte RK, Kirpalani H, Asztalos EV, et al; PINTOS Study Group. Neurodevelopmental outcome of extremely low birth weight infants randomly assigned to restrictive or liberal hemoglobin thresholds for blood transfusion. Pediatrics 2009;123(1): 207-213

53 McCoy TE, Conrad AL, Richman LC, Lindgren SD, Nopoulos PC, Bell EF. Neurocognitive profiles of preterm infants randomly assigned to lower or higher hematocrit thresholds for transfusion. Child Neuropsychol 2011;17(4):347-367

54 ETTNO Investigators. The 'Effects of Transfusion Thresholds on Neurocognitive Outcome of Extremely Low Birth-Weight Infants (ETTNO)' Study: Background, Aims, and Study Protocol. Neonatology 2012;101(4):301-305 